Accepted Manuscript

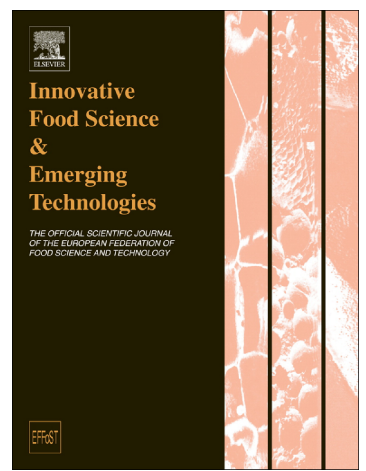

PII:

S1466-8564(18)31444-9

DOI:

https://doi.org/10.1016/j.ifset.2019.102178

Article Number:

102178

Reference:

INNFOO 102178

To appear in:

Innovative Food Science and Emerging Technologies

Received date:

24 November 2018

Revised date:

29 January 2019

Accepted date:

13 June 2019

Please cite this article as: E.C. Crofton, C. Botinestean, M. Fenelon, et al., Potential applications for virtual and augmented reality technologies in sensory science, Innovative Food Science and Emerging Technologies, https://doi.org/10.1016/j.ifset.2019.102178

This is a PDF file of an unedited manuscript that has been accepted for publication. As a service to our customers we are providing this early version of the manuscript. The manuscript will undergo copyediting, typesetting, and review of the resulting proof before it is published in its final form. Please note that during the production process errors may be discovered which could affect the content, and all legal disclaimers that apply to the journal pertain. 
Potential applications for virtual and augmented reality technologies in sensory science

Crofton, E.C ${ }^{a}$., Botinestean, $C^{a}$., Fenelon, $M^{b}$., and Gallagher $E^{a}$

$\mathrm{a}=$ Teagasc Food Research Centre, Ashtown, Dublin, Ireland

$b=$ Teagasc Food Research Centre, Moorepark, Ireland 


\title{
Potential applications for virtual and augmented reality technologies in sensory science
}

\begin{abstract}
Sensory science has advanced significantly in the past decade and is quickly evolving to become a key tool for predicting food product success in the marketplace. Increasingly, sensory data techniques are moving towards more dynamic aspects of sensory perception, taking account of the various stages of user-product interactions. Recent technological advancements in virtual reality and augmented reality have unlocked the potential for new immersive and interactive systems which could be applied as powerful tools for capturing and deciphering the complexities of human sensory perception. This paper reviews recent advancements in virtual and augmented reality technologies and identifies and explores their potential application within the field of sensory science. The paper also considers the possible benefits for the food industry as well as key challenges posed for widespread adoption. The findings indicate that these technologies have the potential to alter the research landscape in sensory science by facilitating promising innovations in five principal areas: consumption context, biometrics, food structure and texture, sensory marketing and augmenting sensory perception. Although the advent of augmented and virtual reality in sensory science offers new exciting developments, the exploitation of these technologies is in its infancy and future research will understand how they can be fully integrated with food and human responses.
\end{abstract}

\section{Industrial relevance}

The need for sensory evaluation within the food industry is becoming increasingly complex as companies continuously compete for consumer product acceptance in today's highly innovative and global food environment. Recent technological developments in virtual and augmented reality offer the food industry new opportunities for generating more reliable insights into consumer sensory perceptions of food and beverages, contributing to the design and development of new products with optimised consumer benefits. These technologies also hold significant potential for improving the predictive validity of newly launched products within the marketplace. 


\section{Introduction}

Sensory evaluation is a scientific discipline that is used to understand how humans perceive and respond to the various stimuli in food using the five senses of sight, smell, touch, taste and hearing. From a fundamental perspective, it attempts to understand the intricacies of sensory perception and consumer behaviour, while at an applied level it can be used as a tool across the product development process to characterise and understand how the sensory properties of food drive consumer decision making and hedonic response (Kemp, $\mathrm{Ng}$, Hollowood \& Hort, 2018). For many years, sensory data was based on averaging sensory responses from consumers evaluating foods under controlled conditions in a sensory laboratory (Hathaway \& Simons, 2017), and was simply viewed by industry as a means for comparing the acceptability and competitiveness of food products within the marketplace (Tuorila \& Monteleone, 2009). However, in the current highly competitive and global food environment, the need for sensory information is becoming increasingly complex, as industry face constant pressure to develop high quality food products at reduced time-tomarket (Delarue, 2015). Over the past decade, advancements in digital technologies, such as smartphones and social media applications, have stimulated a new era of consumer connectivity, providing researchers with opportunities to collect new types of sensory information (Jaeger \& Porcherot, 2017; Jaeger et al., 2017). As a result, the range and sophistication of techniques available for capturing and deciphering consumer's sensory perceptions towards food is evolving substantially to meet industry demands. Sensory evaluation is being increasingly applied by companies in both developed and emerging markets, as a powerful tool for predicting product success across a range of industrial functions including research and development, quality control and marketing (Delarue, 2015; Kemp et al, 2018).

As the digital world continues to evolve at a rapid pace, new virtual reality (VR) and augmented reality $(A R)$ technologies are emerging with the potential to transform the landscape for collecting and processing sensory and consumer information. Although both virtual and augmented reality have existed in various forms for decades (Ong \& Nee, 2004), it is only recently these technologies have advanced to a point of radically changing how people connect and interact with the world (Porcherot et al., 2018; Velasco, Obrist, Petit \& Spence, 2018). Research on the industrial applications for VR and AR is a strong and rapidly 
growing area, with the market for these technologies projected to reach $\$ 162$ billion by 2020 (Business Insider, 2016). Recent technological developments in VR and AR are already showing a demonstrable impact across a number of industries including healthcare (Silva et al., 2018), manufacturing (Bottani \& Vignali, 2018), engineering (Singh \& Erdogdu, 2004), entertainment (Aukstakalnis, 2017), education (Merchant, Goetz, Cifuentes, KeeneyKennicutt \& Davis, 2014), automotive (Lawson, Salanitri \& Waterfield, 2016) and travel (Gibson \& O'Rawe, 2018). For example, within industrial manufacturing these technologies have been applied throughout the production process from initial product design and assembly operations, through to enabling real-time discussions between multidisciplinary teams located at across the globe, resulting in fewer design flaws, enhanced workflow efficiency and increased savings in terms of costs and man-hours (Aukstakalnis, 2017). Beyond manufacturing, AR technology is being used by the automotive industry to support accident and emergency services. For example, Mercedes Benz are placing quick response (QR) codes on the B-pillars and fuel doors of all new cars, enabling first responders to quickly view colour-coded images of wiring and fuel systems using an AR mobile application (Etherington, 2016). As these technologies open up a world of possibilities for transforming the real world and how people interact with it, the food industry is now endeavouring to understand how to capitalise on these digital tools for competitive gain. The focus of this paper is to review recent advancements in virtual and augmented reality technologies and to explore their potential applications within the field of sensory science, highlighting the potential benefits for the food industry and outlining the challenges that currently exist for widespread adoption of these technologies.

\section{Recent advancements in virtual and augmented reality technologies}

\subsection{Virtual reality}

Although virtual reality and augmented reality are both evolving interface systems for displaying digital information, they are distinct technologies with fundamental differences in the type of computing systems required to experience them. Due to continuous advances in core enabling technologies and the conflicting meaning of the words virtual and reality, the term virtual reality has been exceptionally difficult to define and no single definition exists in current literature as a result (Aukstakalnis, 2017). Generally, VR is described as an immersive 
human-computer interaction in which an individual can explore and interact with a threedimensional computer-generated environment. A VR experience is typically accomplished through the use of a stereoscopic head mounted display (HMD) which completely replaces the user's view of the real physical world with an interactive synthetic environment (Siegrist et al., 2018; Silva et al., 2018). Virtual reality as a concept is not entirely new, and dates back to the late 1950s when Morton Heilig, an American cinematographer, developed (and later patented) the Sensorama, an arcade-style cabinet which stimulated the senses through the use of stereoscopic 3D images, stereo speakers, fans and a vibrating chair. The Sensorama is considered one of the earliest examples of immersive, multisensory technologies. In the late 1960s, computer graphics pioneer Ivan Sutherland, alongside his student Bob Sproull, engineered what is widely considered to be the first HMD system known as the Sword of Damocles (Sutherland \& La Russa, 2017). The weight of the system required it to be suspended from the ceiling, but the technology was capable of tracking the movement of the user's head, and could display simple 3D wireframe images in the user's viewing direction. Throughout the 1960s and 1970s, the United States government, particularly the National Science Foundation, Department of Defence, and the National Aeronautics and Space Administration (NASA) were also involved in their own research efforts, which yielded a large pool of skilled researchers in areas such as computer graphics, network infrastructure and simulation modelling (Lowood, 2018; Sutherland \& La Russa, 2017). However, the term virtual reality was not popularised until the late 1980s, when Jason Lanier, founder of VPL Research, developed the first commercially available VR products including the Dataglove and the EyePhone head mounted display (Lauria \& Ford-Morie, 2015).

Between these early systems and today, major advances in computational power and visualisation and tracking technologies have given rise to a new era of affordable, fully immersive stereoscopic HMDs that are widely available to consumers. Nowadays, there is a multitude of VR HMD devices on the market ranging from high-end PC-based or "tethered" display systems to lower end devices driven by smartphones. While the majority of VR systems developed to date focus on controlling the user's visual and auditory experiences, technologies such as haptic gloves and full-body haptic suits are being increasingly used for adding tactile and kinaesthetic content across a range of VR applications (Aukstakalnis, 
2017; Gallace \& Spence 2014). Haptic gloves, such as CyberGrasp ${ }^{\mathrm{TM}}$, Dexmo ${ }^{\mathrm{TM}}$ and HaptX, are capable of stimulating the sense of touch by transmitting tactile inputs (e.g. vibrations and pressure) to the user's skin using force feedback technology. However, effectively reproducing tactile sensations within a VR system poses considerable technological challenges due to the complexity of the human nervous system (Aukstakalnis, 2017; Perret \& Vander-Poorten, 2018).

In terms of PC-based VR, the Oculus Rift and HTC Vive were the first modern, commercially available platforms to retrigger the public's interest in virtual reality technology. Following the pre-release of two developer models and acquisition of Oculus by Facebook for $\$ 2$ billion dollars, the consumer version of Oculus Rift was released in early 2016. VR competitor to the Oculus Rift, HTC Vive, was released one month later following collaboration between Valve Corporation and smartphone manufacturer, HTC (Sutherland \& La Russa, 2017). Both HMDs are equipped with a high resolution display of 1080x1200 pixels per eye with a field of view extending 110-degrees, and have built-in sensors for tracking the position and orientation of the user using six degrees-of-freedom, enabling the user to move around the virtual space. Additionally, motion-tracked controllers allow the person to use their hands to intuitively manipulate virtual objects and interact with the computer simulation, further enhancing the feeling of immersion (Siegrist et al., 2018). While PC driven VR undoubtedly offers the most powerful immersive experience of modern VR technology, the headsets are expensive and require the user to be physically tethered to a computer with advanced processing power. As a result, mainstream adoption of consumer PC VR has been primarily in the gaming industry to date (Aukstakalnis, 2017). Nonetheless, new headsets are increasingly being launched into the market delivering more sophisticated levels of technology. For example, the HTC Vive Pro, launched in April 2018, provides wireless capability and features a $78 \%$ resolution increase to $1400 \times 1600$ per eye, promising the consumer a more immersive and comfortable VR experience (Warren, 2018).

Advancements in smartphone technology (e.g. increased processing power, higher pixel counts, and high-performance sensors) have played an integral role in connecting consumers to virtual worlds. Smartphone-based VR requires a headset with custom lenses in which a user can simply insert a compatible phone. Smartphone VR devices currently available on the market include Google cardboard, Samsung Gear VR and Google Daydream. 
The VR content is processed by the software on the smartphone, and the movement of the users head is tracked by the phone's internal inertial measurement unit (IMU) which generally only supports three degrees of freedom tracking (Aukstakalnis, 2017; Sutherland \& La Russa, 2017). This permits the user to look in every direction around them (side to side, up and down, forwards and backwards), but their position is fixed, meaning it's not possible to interact or move around the virtual space. Due to limitations in positional tracking and computational power, smartphone-driven VR provides a considerably less immersive experience in comparison to PC-based platforms. Nonetheless the accessibility and lower production cost of these headsets has encouraged the sizeable and widespread uptake of VR among digitally-savvy consumers (Flavián, Ibáñez-Sanchez \& Orús, 2018; Lamkin, 2017). Smartphone HMDs are commonly used for viewing simple 360-degree videos, which is a real-world video recording where every angle is captured with an omnidirectional camera (or several cameras) and subsequently stitched together to generate an immersive experience for the user (Sutherland \& La Russa, 2017). It is argued however, that immersive content based on 360-degree video technically does not constitute a true virtual reality experience which by definition requires computer generated imagery (Aukstakalnis, 2017; Siegrist et al., 2018). 360-degree videos are typically described in the context of virtual reality by marketers seeking new, innovative tools for creating more immersive and engaging brand experiences for consumers.

Beyond PC and mobile based VR platforms, the latest innovations in VR technology have given rise to a new category of 'standalone' portable headsets such as the Oculus Go, Lenovo Mirage Solo, and the upcoming HTC Vive Focus. These headsets are capable of generating a highly immersive virtual experience without the use of a computer or smartphone, offering a convenient and affordable alternative to existing systems on the market (Brewster, 2018).

\subsection{Augmented reality}

Augmented reality is a relatively newer form of human-computer interaction which superimposes computer-generated information into a person's view of the real world, creating an illusion where both virtual and real objects coexist in the same space (Ong \& Nee, 2004). Therefore, AR can be differentiated from VR, given that the former overlays 
digital information in a real environment, rather than completely replacing it. In addition to combining real and virtual information, a true AR system should run interactively in real time, and seamlessly align natural world and virtual objects with each other (Azuma et al., 2001; Kipper \& Rampolia, 2013). While AR technology to date has been confined to overlaying visual imagery onto the real world, advancements in speech recognition technologies are extending AR to audio-based platforms. A promising breakthrough innovation in this area is by Bose Corporation, who recently established a $\$ 50$ million venture fund to develop audio-driven AR glasses which will combine motion sensors, built-in speakers and GPS data to intuitively augment sound in the users surrounding environment (Robertson, 2018). The earliest technological development in AR can be traced back to Ivan Sutherland's work on the Swords of Damocles HMD. Although the Swords of Damocles system is widely considered one of the earliest examples of VR technology, the headset was transparent in places and therefore is argued to also represent one of the earliest innovations enabling modern AR devices (Aukstakalnis, 2017; Azuma et al., 2001; Kipper \& Rampolia, 2013). The term 'augmented reality' was later coined in the early 1990s by Boeing researcher Tom Caudell to describe a system for assembling electrical cables in aircrafts (Caudell \& Mizell, 1992). However, due to technological limitations in both hardware and software, AR developments in the years that followed were primarily confined to research laboratories, and even in the present day, AR does not yet have the same degree of technological maturity in comparison to VR (Azuma et al., 2001; Sutherland \& La Russa, 2017).

Two primary platforms currently exist for displaying AR information: handheld displays such as smartphone and tablets, and AR-enabled HMDs. Although providing an arguably lower end experience, smartphones represent the most common distribution channel for AR in the consumer market. With the recent release of software development platforms ARCore and ARKit for Android and iOS devices respectively, building AR smartphone applications is becoming increasingly easier for developers (Mealy, 2018; Linowes \& Babilinski, 2017). Perhaps the most successful application to capture public attention of AR technology has been Pokémon Go. The application, which was launched in 2016, anchors avatars in the real world using the camera on a mobile device, and has been reportedly downloaded 800 million times since its launch (Lanier, 2018). In a typical AR system, the camera in a 
smartphone is used to scan a specially designed marker, such as a QR barcode or image, which calculates the camera's position in relation to the environment and projects visual AR content through the screen. While the technology enabling 'marker-based' AR is well developed and easy to use, the requirement of a specific physical marker may limit its potential application in the food industry. As technology continues to advance, AR systems are increasingly transitioning to markerless AR, which typically uses the devices features such as GPS, camera, hybrid vision and accelerometers to adjust the surrounding environment and control the alignment between real and virtual objects, without the need of a physical marker (Kipper \& Rampolia, 2013; Comport, Marchand, Pressigout \& Chaumette, 2006). Nonetheless, both techniques require the user to constantly hold the smartphone in the same position, providing a less convenient experience for the user.

The most well-known AR enabled HMDs available on the market at the time of writing include Magic Leap One, Meta, and Microsoft Hololens. These headsets support much more sophisticated levels of technology than their smartphone counterparts, including voice recognition, spatial mapping, and gesture detection (Dickson, 2018). These devices typically take the form of large, transparent HMDs which overlay spatially correlated, high-definition digital content within the users' physical surroundings. Due to the cost, bulkiness and a lack of consumer need beyond entertainment, these AR headsets are primarily targeted towards industry as a visualization tool for enhancing workflow efficiency or meeting an information need (Aukstakalnis, 2017; Kipper \& Rampolia, 2013). Although AR is still in its infancy from a consumer perspective, hardware platforms enabling AR technology are advancing at a rapid pace, and is evident by the recent proliferation of wearable AR glasses into the marketplace (Lamkin, 2018). Indeed, research efforts in AR technology have also extended to contact lenses, which will be designed to detect and display digital information onto the wearer's retina with the blink of an eye (Kim et al., 2016; Kipper \& Rampolia, 2013). As the immense potential for AR technology begins to unfold, those working in the field believe that AR will soon become an integral part of society, leading to the eventual demise of the smartphone (Carroll, 2017). However, it is unlikely that neither AR nor VR will ever reach mainstream adoption unless industry identifies a genuine consumer need for the technologies, and proves to make a demonstrable contribution in the daily activities of people's lives. 


\section{Potential applications for virtual and augmented reality in sensory science}

As virtual and augmented reality technologies continue to evolve (as discussed above), the possibilities for using these technologies in a myriad of speciality application markets will continue to grow. In the following section, the potential applications for these technologies within the field of sensory science will be discussed.

\subsection{Context enhancing technologies}

It is widely accepted that consumers' emotional and hedonic responses are shaped by the context in which a food is consumed. For example, an average tasting wine may be perceived as enjoyable and memorable if consumed in the company of family and friends. Recently, there has been significant interest among sensory scientists in gaining a better understanding of consumption context in consumer sensory testing (Jaeger et al., 2017; Jaeger \& Porcherot, 2017; Hein, Hamid, Jaeger \& Delahunty, 2010). The reason for this increase in interest is not surprising. Despite decades of research demonstrating the usefulness of consumer sensory laboratory tests in identifying products of poor sensory quality, it is evident that data derived from these tests cannot reliably predict the success of a product within the first few years of launch. Therefore it is not uncommon for products perceived as favourable in consumer trials to quickly fail once entering the marketplace (de Wijk, Kooijman, Verhoeven, Holthusen \& de Graaf, 2012; Köster, 2009). Although multiple factors can influence the poor predictive validity of newly launched products, conducting consumer sensory tests in isolated sensory booths devoid of environmental contextual cues could be a contributing factor (Hathaway \& Simons, 2017; Bangcuyo et al., 2015). The highly controlled setting of a sensory laboratory does not accurately reflect real life conditions, and fails to consider the impact of contextual information in forming sensory perceptions and acceptance.

Several approaches have been taken to study consumption context in consumer sensory testing. Written or imagined scenarios have been used to evoke certain situations or contexts, (Hein et al., 2010), while more realistic and ecologically valid environments have been created such as The Restaurant of the Future in Wageningen, Netherlands, which is elaborately rigged with state of the art technology for observing consumer eating and drinking behaviour. More recently, physical immersive environments, such as a bar (Sester 
et al., 2013), coffeehouse (Bangcuyo et al., 2015) or aeroplane (Holthuysen, Vrijhof, de Wijk \& Kremer, 2017) have been set-up using a combination of visual, auditory, olfactory and tactile stimuli for communicating contextual information to the consumer. Although only a handful of context conditioning studies have utilised physical immersive environments, the results to date have been promising, showing heightened consumer engagement and delivering more discriminative and predictive hedonic responses compared to a controlled laboratory setting (Hathaway \& Simons, 2017; Holthuysen et al., 2017; Kim et al., 2016; Bangcuyo et al., 2015; Sester et al., 2013) . However, while recreating a physical immersive environment could improve the ecological validity of research, it requires a relatively large amount of space and can be a rather expensive and time-consuming task.

An immersive VR environment can elicit vivid perceptual experiences, inducing a strong sense of presence whereby the user genuinely feels removed from the real world (Schnack, Wright \& Holdershaw, 2018; Gallace, Ngo, Sulaitis \& Spence, 2012). Contextual or surrounding stimuli (e.g. colours, furniture etc.) can also be easily manipulated using VR technology, providing an innovative tool for understanding the impact of different contexts on emotional and hedonic ratings. From a research perspective, a number of different approaches have been used for adapting VR technology in consumer product evaluations. For example, Andersen, Kraus, Ritz, \& Bredie (2018) studied the impact of exposure to a secluded sunny beach situation on desires for beverages using a 360-degree VR video displayed through a HMD device. Other authors have also recently used 360-degree VR to explore the effects of different environments (park bench, cow barn, and a sensory booth) on sensory perception of blue cheese (Stelick, Penano, Riak \& Dando, 2018). While 360 degree-VR video is a relatively easy and inexpensive approach for enhancing context in consumer sensory evaluations, there are a number of limitations which need to be considered. For instance, haptic cues are absent from 360 degree VR as subjects are unable walk around or interact with the surrounding environment, which might have a profound impact on their perceived sense of presence. In addition, a 360-degree VR is a pre-recorded video which fully replaces the user's view of the real world, meaning the HMD would need to be removed to enable sensory assessments of food products. This would effectively break the user's level of immersion and possibly hinder their ability to perform the sensory task in a reliable manner. In other approaches, aspects of consumer food behaviour were studied 
in entirely 3D computer-generated VR environments, such as a supermarket (Schnack et al., 2018; Siegrist et al., 2018; Verhulst, Normand, Lombard \& Moreau, 2017) or food buffet (Persky, Goldring, Turner, Cohen \& Kistler, 2018; Ung, Menozzi, Hartmann \& Siegrist, 2018), in which participants could walk around and become immersed in the virtual space using a HMD. These studies provide interesting insights into how consumers select food in a VR world, demonstrating that behaviour in VR is in many respects similar to behaviour in real life. However, it should be considered that consumer's choice or sensory perception of foods in a completely virtual environment could be heavily dependent on the visual realism of the food image depicted. For instance, fruits and vegetables could be perceived as less appealing in VR than in the real world (Siegrist et al., 2018). This potential limitation could be overcome by using a form of augmented reality called mixed reality, in which a specific HMD, such as Microsoft Hololens, can integrate specific elements from the real environment, such as food or the person hands, within the surrounding VR space (Korsgaard, Bjoner \& Nilsson, 2018). However, regardless of the approach, it must be kept in mind that research on the contextual effects VR / AR environments is in its infancy, and further research is necessary to facilitate their confident application in improving the reliability of consumer sensory evaluations.

\subsection{Biometrics}

Eating is a multisensory experience during which the brain interprets and connects the various sensory stimuli in a food product with previously stored information to form our perception of flavour. During traditional hedonic tests, sensory data is collected using explicit measures, whereby consumers are instructed to evaluate specific product attributes for acceptability or preference by indicating their perceived sensory response on some type of scale. More recently, there has been a dramatic rise in hedonic tests incorporating selfreported emotional measures in an effort to gain deeper insights into consumer-product interactions (Jaeger et al., 2018; Dorado, Chaya, Tarrega \& Hort, 2016; Ng, Chaya \& Hort, 2013). While data generated from these studies is important for informing the development of food products, self-reported assessments rely on the use of conscious and rational reasoning (Torrico et al., 2018a; de Wijk et al., 2012), and therefore the accuracy of the data is dependent on the individual's ability to articulate their hedonic and emotional perceptions to food stimuli. However, research has highlighted that consumer choices are 
also shaped by mechanisms which exist below the level of consciousness (Köster, 2009) therefore it is likely that hedonic and emotional responses processed at an unconscious level by the brain cannot be verbally articulated, even though they play an important role in the way people select and consume foods.

The application of biometric technology for characterising consumers based on their unconscious responses towards food stimuli is a growing area of interest within the arena of sensory and consumer science (Torrico et al., 2018b; Jaeger et al., 2017). Biometric data is typically collected using a device comprising a range of sophisticated sensors which measure and analyse an individual's unique physiological or behavioural characteristics. Biometrics is already integrated into our everyday life. For instance, wearable fitness trackers, such as the Fitbit, use the technology for monitoring personal health and lifestyle information, while the latest smartphones feature fingerprint and facial recognition to unlock devices. The global market for biometric devices and applications is also developing rapidly, with particular growth expected in industries including mobile, healthcare, travel and banking in the coming years (Moeller, 2018). From a sensory research perspective, biometric techniques have been applied to implicitly measure the body's involuntary or behavioural reactions to food stimuli, which can be a direct indicator of an individual's emotional state. The most commonly studied measures to date include involuntary physiological responses governed by the Autonomic Nervous System (ANS) including heart rate, skin temperature, respiratory patterns and skin conductivity. These types of responses have been investigated in the context of a number of product types such as beer (Beyts et al., 2017), juice (VerasteguiTena, van Trijp \& Piqueras-Fiszman, 2019) and chocolate (Torrico et al., 2018a). Other biometric measures of interest include capturing facial expressions using either electromyography (EMG) (Beyts et al., 2017) or a Facial Action Coding System (He, Boesveldt, de Graaf, de Wijk, 2016; de Wijk et al., 2012); recording eye movements using eye-tracking technology (Siegrist, Leins-Hess \& Keller, 2015); and to a lesser extent, recording brain wave rhythms using electroencephalography (EEG) (Viemose et al., 2013). While the application of biometrics in sensory science is relatively new, combining these techniques provide an opportunity to capture novel multidimensional data for relating unconscious responses to various stages of consumer-product interactions, removing the biases associated with traditional methods, and enriching our understanding of the 
emotions responsible for driving product acceptance in the real world (He et al., 2016; de Wijk et al., 2012).

With developments in next generation virtual and augmented reality technologies emerging concurrently with advancements in biometrics, there is potential for integrating these technologies for future sensory and consumer research applications. In theory, both VR and AR technologies could eventually integrate all the biometric techniques mentioned above, however, based on recent technological innovations, eye-tracking and facial recognition will likely garner most attention in coming years. For instance, in early 2018, Tobii released eyetracking technology which can be added to a retrofitted version of the HTC Vive headset (Hardawar, 2018), enabling researchers the opportunity to measure consumer visual attention within a controlled VR environment. The integration of eye-tacking technology within a VR headset also has the added advantage of creating the impression of higher quality graphics using a technique called foveated rendering, which only renders high definition graphics in the area the person is focussed on, while reducing the picture quality everywhere else. Therefore, rendering an immersive VR environment requires less processing power, enabling a higher quality VR experience using lower-end devices such as mobile phones (Mealy, 2018). In addition to eye-tracking, technology firm, Mindmaze, have designed a nuero-sensitive foam comprising a ring of sensors which can be inserted into the faceplate of any VR headset. The foam-based insert, called Mask, uses biometric technology to detect user's facial expressions and translates the emotion expressed through virtual avatars in real time (Burn, 2017). Although the Mask is a relatively simple creation, it demonstrates the potential to capture consumers' emotional responses using facial recognition technology while immersed in a VR world. Research efforts have also begun to incorporate facial recognition and eye-tracking technology in augmented reality devices, making it possible in the future for people walking the streets to instantly retrieve digital data, such as social media history, for people passing by (Swaminathan \& Ramachandran, 2018; Kipper \& Rampolia, 2013). Furthermore, it has been reported that companies, such as Facebook, are building non-invasive brain computer interfaces $(\mathrm{BCl})$ for $A R$ and VR headsets whereby the brain will communicate directly with the technology, enabling users to eventually control their digital experiences with their mind (Constine, 2017). While this may prove unrealistic, prior $\mathrm{BCl}$ research has successfully demonstrated the ability to navigate a 
virtual street using thought-modulated electroencephalogram (EEG) brain signals (Pfurtscheller et al., 2006).

While it's abundantly clear that the true potential for these applications remains to be seen, combining biometrics with $\mathrm{VR} / \mathrm{AR}$, in conjunction with explicit measures, could be used to build sophisticated models predicting an individual's sensory preference and liking of food products. Although the interplay between biometrics and VR/AR is advancing at a rapid pace, a key challenge will be the accurate collection and processing of such complex datasets in a manner that generates reliable insights into consumer sensory perceptions of food.

\subsection{Food structure and texture}

The breakdown of food in the mouth is a highly dynamic process which is influenced by both the food's structure and a series of complex oral manipulations involving the mouth (teeth, tongue and palate) and saliva secretion. During eating, the structure of food is physically transformed from its initial shape and size to a state at which it can be safely swallowed. It is widely accepted that the textural sensory properties perceived as food is broken down in the mouth has a profound influence on consumer choice and product acceptability. However, texture is considered a multidimensional food property and consequently the determining mechanisms governing perception are difficult to understand. Texture perception is dynamic in nature, meaning the textural sensations detected in the initial stages of food breakdown could be very different from those perceived at the end. It is well recognized the structural properties of food are intrinsically linked to food texture (de Lavergne, van de Velde \& Stieger, 2017; Chen \& Stokes, 2012), and a range of imitative mechanical and rheological measurements can be used to instrumentally predict key aspects of texture perception during the very initial stages (e.g. first bite) of eating. However, due to the complexities of oral food breakdown, it is not currently possible, using existing techniques, to instrumentally predict responses to perceptual judgments of changing texture which arise as the food is transformed after the initial few seconds of breakdown (Stokes, Boehm \& Baier, 2013; Chen \& Stokes, 2012). In order to design texturally optimised food products, it is necessary to better understand the interplay between food structure and sensory perception across the dynamics of food oral 
processing. A number of studies have been recently undertaken in this area (Santagiuliana, Christaki, Piqueras-Fiszman, Scholten, \& Stieger, 2018; Witt \& Stokes, 2015; Stokes, et al., 2013).

Currently, many different imaging techniques exist for capturing and understanding various aspects of food structure, which can include simple 2-dimensional (2D) images of sections and surfaces, as well as more complex 3-dimensional (3D) images of internal structures. However, viewing a 3D image on a 2D flat panel display, such as a computer screen, lacks depth perception and limits the accuracy of quantitative 3D image analysis (Wheeler et al., 2018; Bassel, 2015). Virtual and augmented realities are emerging as innovative technologies for visualising computationally intense digital data. The application of VR / AR as visualisation tools is gaining particular attention within the healthcare sector, and is already showing demonstrable results in facilitating medical interventions and enhancing the area of education and training (Aukstakalnis, 2017; Sutherland \& La Russa, 2017). For instance, novel VR applications such as VRVisu, ConfocalVR, Arivis InViewR and Echopixel True 3D have the capability to reconstruct complex images from real-world medical datasets into real 3D immersive experiences, enabling medical practitioners to treat patients more effectively (Silva et al., 2018; Stefani, Lacy-Hulbert \& Skillman, 2018; Reddivari, Smith \& Pabalate, 2017). Augmented reality has also been recently adopted in medical practice whereby one of the UK's largest children's hospitals is exploring Microsoft Hololens for interactive visualization of 3D images of patient heart or brain scans during surgery (Palladino, 2018).

Adapting these technologies within the food industry has the potential to revolutionise research methodologies for the 3D visualisation of internal structures in food. For example, x-ray micro-computer tomography $(\mu \mathrm{CT})$ is currently being used by food scientists as a nondestructive and non-invasive imaging technique for studying the 3D structure of ingredients and foods (Schoeman, Williams, du Pleissis \& Manley, 2016 and Léonard, Blacher, Nimmol \& Devahastin, 2008). By taking this technique (and others such as MRI) one step further and applying volume rendering to the images produced, the viewing of food structures in a truly 3D form using a VR HMD is enabled. Using handheld controllers, it is possible to acquire measurement data of various aspects of structure while immersed within a computer generated imagery-based VR food. The application of these technologies within food are 
currently being investigated within the Teagasc Food Research Programme in Ireland whereby sophisticated volume rendering techniques in VR have enabled researchers to 'step inside' foods such as bread (Figure 1) and a pig carcass, generating novel quantitative measures of complex food structures which is not possible using existing techniques. These virtual reality systems provide an immersive and engaging tool for researchers to inspect and manipulate the internal structures of foods. Indeed, in the future, these specialised visualisation systems could be advanced to incorporate tactile or audio feedback devices, enabling fascinating possibilities for understanding complex information. Combing data generated using this software with measurements of temporal perceptual changes using appropriate sensory testing techniques, such as Temporal Dominance Sensations (TDS), could provide innovative visualisations for identifying and predicting the impact of a new ingredient addition or applied treatment on texture perception, potentially leading to new manufacturing practices, food products and customer experiences.

\subsection{Sensory marketing}

As consumers become more connected and informed in today's highly competitive food market, companies must create more innovative ways to positively engage with their customers. Over the past decade, an area of psychological research known as 'sensory marketing' has emerged as a strategic tool for designing multisensory food brands intended to stimulate each of the five senses of sight, smell, touch, taste and hearing. Marketing professionals are increasingly focussing on selling consumers an experience, rather than just a product, which has been specifically designed to elicit an emotional association to a specific food brand (Spence, 2019; Kemp et al, 2018). Researchers have studied various aspects of multisensory product design on human sensory perception, such as the effect of external elements like music, sound and smell (Kantono et al., 2016; Spence, 2015a; Spence, 2015b) or the impact of changing the colour, shape or weight of food containers (Kampfer, Leischnig, Sven Ivens \& Spence, 2017; Piqueras-Fiszman, Alcaide, Roura \& Spence 2012). The emergence of virtual and augmented reality technologies has opened a gateway of opportunity to improve sensory marketing efforts within the food industry through stimulating immersive and interactive user experiences. The introduction of affordable VR headsets, along with ARKit and ARCore development software for mobile platforms, is enabling new marketing strategies to be developed for engaging consumers with brand 
messages. For example, companies such as Nestlé, Boursin Cheese and Patrón are using VR storytelling techniques to reveal their entire production process to consumers (Michail, 2017; Arthur, 2015). McDonald's and Coca Cola have released limited-edition packaging which can be transformed into a cardboard VR headset compatible to work with a consumer's smartphone (Filloon, 2016). While Guinness has applied sensory marketing research to design specific VR environments for enhancing the flavour profile of a new line of beers (Kiefer, 2017). Food companies are also attempting to build more meaningful consumer-brand relationships by adding interactive features to their packaging using AR technology. Consumers can use their smartphones to scan food packaging and details regarding sourcing, production, preparation methods or price comparisons are instantly retrieved through the device (Powell, 2018; Watson, 2017). Furthermore, Kabaq (a 3D food technology company) are combining digital rendering and photogrammetry to present consumers with realistic 3D visions of menu options in restaurants before ordering (http://www.kabaq.io/).

While these technologies provide exciting new platforms for sensory marketing, there are barriers which will impede their successful implementation. As mentioned previously, it is unlikely VR / AR will ever reach mainstream consumer audiences without the industry first demonstrating how their technologies provide genuine customer value. Therefore, focused/targeted strategies will need to be developed to encourage consumer adoption. In addition, people perceive the world around them through the multisensory integration of visual, olfactory, auditory, gustatory and tactile stimuli. However, when considering the study of multisensory information using VR / AR technology, the vast majority of research to date has involved the stimulation of one or two sensory modalities at a given time, typically vision and audition, and, to a lesser extent, haptics (Gallace et al., 2012). While noteworthy advances have been made to stimulate olfactory and gustatory experiences within VR and AR systems (Porcherot et al., 2018; Risso, Rodriguez, Bordegoni, \& Gallace, 2018; Stelick et al., 2018; Carulli, Bordegoni \& Cugini, 2016; Dinh, Walker, Song, Kobayashi \& Hodges, 1999), integrating odour and taste stimuli within these environments is challenging and highlights an obvious limitation of these systems. Nevertheless, stimulating multiple sensory modalities simultaneously within a virtual environment has been reported to deliver a perceptually enhanced sensory experience (Gallace et al., 2012; Dinh et al., 1999). As taste 
and smell are integral in multisensory food product design, a key challenge will be associated with building sensory marketing campaigns appealing to multiple senses in a VR / AR setting. It is important that marketing professionals fully understand how these digital platforms form sensory experiences, and develop innovative strategies that will assist in improving these experiences, potentially enhancing brand characteristics and eliciting stronger emotional connections towards food products (Petit, Cheok, Spence, Velasco \& Karunanayaka, 2015).

\subsection{Augmenting sensory perception}

The capacity of augmented reality systems to superimpose digital information over real world views is gaining interest as a means for promoting healthier eating habits. Recently, a number of AR applications for visualising nutritional information have been built for smartphone and tablet devices. For instance, Bayu, Arshad \& Ali (2013) built a prototype AR gauge meter system for visualising the nutritional content of food, which could be utilised by diabetic patients for controlling blood glucose levels. An AR application for conveying nutritional information of drinks ranging in healthiness was also recently proposed (Csakvary, 2017). In addition, an AR tool 'ServAR' was developed and tested with potential users and showed promising results for improving the accuracy of estimating portion sizes of a variety of foods (Rollo, Bucher, Smith \& Collins, 2017). The provision of augmented nutritional information on influencing consumer food choices is currently being investigated at Teagasc Food Research Centre, Dublin, Ireland, whereby new AR applications are being developed taking account of multisensory processing between different sensory modalities. An example of the AR application is shown in Figure 2.

A number of AR-based technologies have also been developed attempting to control food portion size without negatively impacting perceived quantity. For instance, Narumi, Ban, Kajinami, Tanikawa \& Hirose (2012) applied a shape deformation processing method in realtime to augment the volume of food resulting in a $15 \%$ reduction in consumption without changing perceived fullness. The perceived appearance and taste of sweet and savoury food products were also digitally manipulated using a projective AR application and a camera (Nishizawa, Jiang \& Okajima, 2016). In addition, a 'Meta Cookie' AR system for overlaying visual and olfactory information onto a real cookie was shown to change taste experiences 
in over $70 \%$ of participants (Narumi, Nishizaka, Kajinami, Tanikawa \& Hirose, 2011). While the proposed systems demonstrate the potential for AR to manipulate food portion size and sensory perceptions while continuing to maintain consumer satisfaction, small sample sizes were used in each of these studies, and therefore validation of findings would be required with a more representative sample of consumers.

There is also a growing interest in integrating digital flavour augmentation technologies into our daily eating and drinking experiences. Perceptions of basic tastes sensations (sweet, salt, sour and bitter) have been successfully stimulated by applying electrical and thermal stimulation to the human tongue using a digital taste interface, with study participants noting a particularly high perception rate of salty and sour tastes (Nakamura \& Miyashita, 2013; Ranasinghe, Nakatsu, Nii, \& Gopalakrishnakone, 2012). This electrical taste augmentation technique has been integrated into everyday utensils such as a spoon (Ranasinghe, Lee, Suthokumar \& Do, 2016), chopsticks and a soup bowl (Ranasinghe et al., 2018) with results also demonstrating significant increases in saltiness and sourness perception when the utensils were used to consume different food products. Indeed, from a psychological perspective, the visual (e.g. colour) and tactile (e.g. weight) properties of utensils such as plates and cutlery has been shown to elicit perceptions of sweetness and saltiness in real foods (Piqueras-Fiszman et al., 2012; Harrar \& Spence, 2011; Harrar, Piqueras-Fiszman \& Spence, 2011). Therefore, the combined use of electrical taste augmentation with changes in environmental cues such as packaging colour and shape could be used, in theory, to elicit illusory tastes or flavours perceptions, enabling food manufactures to reduce the salt or sugar content of foods without a detrimental impact on sensory quality.

Beyond augmenting flavour experiences, a large interdisciplinary research project is also underway investigating the how virtual reality technologies and computational gastronomy can be merged to create multisensory eating experiences with the possibility of health or nutrition benefits (www.projectnourished.com). Within sensory science, these technologies could be used to create or augment novel flavour experiences, or elicit heightened flavour sensations in people with impaired taste acuity such as older consumers or cancer patients (Ranasinghe et al., 2018). While the prospect of digitizing flavour perception is exciting, whether these technologies will be adopted in a commercial setting in the next 5 years or 50 
years is impossible to predict. Nonetheless, the challenge lies for food manufactures to leverage the advantages these technological systems have to offer.

\section{Conclusion}

This paper provides, to the best of our knowledge, the first review of the emerging opportunities for virtual and augmented reality technologies across the discipline of sensory science. The review highlights the potential benefit for these technologies within the food industry and outlines the challenges which currently exist for widespread adoption. The findings indicate that VR and AR hold significant potential to become major computing platforms within sensory science, facilitating initial promising innovations in five key areas: consumption context, biometrics, food structure and texture, sensory marketing and augmenting sensory perception. The results show that VR and AR can be applied as contextenhancing technologies by replacing real environments with immersive settings, improving the ecological validity of research and allowing for a better prediction of consumer sensory evaluations. In the area of biometrics, VR and AR can integrate a range of techniques (e.g. eye-tracking and facial recognition) for capturing consumers' unconscious and unbiased emotional responses towards food products, providing deeper insights into consumer food choice and preferences. VR and AR can also enable the interactive visualisation of complex food ingredient structures and their interplay with dynamic sensory data, enhancing our understanding of oral food processing, potentially leading to new manufacturing practices, food products and customer experiences. In addition, augmenting flavour or nutritional information could induce expectations of satiation, ultimately reducing the amount of food consumed. Finally, in sensory marketing these technologies could stimulate multiple senses simultaneously providing exciting new eating experiences for consumers. While it is clear that VR and AR will play a transformative role in many aspects of sensory science, the application area is exceptionally young and future research will understand how they can be fully integrated with food and human responses. VR and AR technologies will continue to evolve at a rapid pace; devices will become smaller, more affordable and inevitably become key digital communication and social platforms for consumers in the future. However, mainstream adoption of VR and AR devices will be unlikely unless a genuine consumer need for these technologies is identified, and they prove to make a demonstrable contribution in 
consumers' everyday life. The enabling technologies have been developed; the next step involves creating the innovative applications.

\section{References:}

Andersen, I.N.S.K., Kraus, A.A., Ritz, C., \& Bredie, W.L.P. (2018). Desires for beverages and liking of skin care product odors in imaginative and immersive virtual reality beach contexts. Food Research International, in press: https://doi.org/10.1016/j.foodres.2018.01.027.

Arthur, R. (2015). Nescafé and Google in virtual reality coffee experience: https://www.beveragedaily.com/Article/2015/09/30/Nescafe-and-Google-launch-virtualreality-coffee-experience / Accessed 8 November 2018.

Aukstakalnis, S. (2017). Applications of augmented and virtual reality in science and engineering. Practical augmented reality: A guide to the technologies, applications and human factors for $A R$ and VR. America: Pearson Education.

Azuma, R., Baillot, Y., Behringer, R., Feiner, S., Julier, S., \& Maclntyre, B. (2001). Recent advances in augmented reality. IEEE Computer Graphics and Applications, 21: 6.

Bangcuyo,R.G., Smith, K.J., Zumach, J.L., Pierce, A.M., Guttman, G.A., \& Simons, C.T. (2015). The use of immersive technologies to improve consumer testing: The role of ecological validity, context and engagement in evaluating coffee. Food Quality and Preference, 41, 8495.

Bassel, G.W. (2015). Accuracy in Quantitative 3D Image Analysis. Plant Cell, 27, 950-953.

Bayu, M.Z., Arshad, H., \& Ali, N.Z. (2013). Nutritional information visualization using mobile augmented reality technology. Procedia Technology, 11, $396-402$.

Beyts, C., Chaya, C., Dehrmann, F., James, S., Smart, K., \& Hort, J. (2017). A comparison of self-reported emotional and implicit responses to aromas in beer. Food Quality and Preference, 59, 68-80.

Bottani, E., \& Vignali, G. (2018). Augmented reality technology in the manufacturing industry: a review of the last decade. IISE Transactions, DOI: $10.1080 / 24725854.2018 .1493244$.

Brewster, S. (2018). The best standalone VR headset. https://thewirecutter.com/reviews/best-standalone-vr-headset/ Accessed 18 September 2018. 
Burn, J. (2017). Neuro-sensitive foam shows your expression in VR before your face does. https://www.forbes.com/sites/janetwburns/2017/04/12/this-neuro-sensitive-foam-insertis-changing-the-face-of-vr/\#2ddbc5963773 / Accessed 30 October 2018.

Business Insider UK. (2016). The virtual and augmented reality market will reach \$162 billion by 2020. http://uk.businessinsider.com/virtual-and-augmented-reality-markets-will-reach162-billion-by-2020-2016-8 / Accessed 12 October 2018.

Carroll, A. (2017). How augmented reality will change customer experience. https://irishtechnews.ie/how-augmented-reality-will-change-customer-experience/ / Accessed 10 October 2018.

Carulli, M, Bordegoni, M., \& Cugini, U. (2016). Integrating scents simulation in virtual reality multisensory environment for industrial products evaluation. Computer-aided designs and applications, 13, 320-328.

Caudell, T.P. \& Mizell, D.W. (1992). Augmented reality: an application of heads-up display technology to manual manufacturing processes. Proceedings of the Twenty-Fifth Hawaii International Conference on System Sciences, 2:659-669.

Chen, J., \& Stokes, J.R. (2012). Rheology and tribology: Two distinctive regimes of food texture sensation. Trends in Food Science and Technology, 25, 4-12.

Comport, A., Marchand, E., Pressigout, M., \& Chaumette, F. (2006). Real-time markerless tracking for augmented reality: the virtual visual servoing framework. IEEE Transactions on Visualization and Computer Graphics, 12, 615-628.

Constine, J. (2017). Facebook is building brain-computer interfaces for typing and skinhearing. https://techcrunch.com/2017/04/19/facebook-brain-interface/ Accessed November 2018.

Csakvary, B. (2017). Promoting healthier food choices with the application of Augmented Reality (Masters Thesis). Netherlands, Wageningen University.

Delarue, J. (2015). The use of rapid methods in R\&D and research: an introduction. In J. Delarue, B.L. Lawlor, \& M. Rogeaux (Eds.), Rapid sensory profiling techniques (pp. 3-25). UK: Woolhead Publishing.

de Lavergne, M.D., van de Velde, F., \& Stieger, M. (2017). Bolus matters: the influence of food oral breakdown on dynamic texture perception. Food Function, 8, 464-480.

de Wijk, Kooijman, V., Verhoeven, R.H.G., Holthuysen, N.T.E., \& de Graaf, C. (2012). Autonomic nervous system responses on and facial expressions to the sight, smell, and taste of liked and disliked foods. Food Quality and Preference, 26, 196-203. 
Dickson, B. (2018). 4 reasons AR glasses won't replace your smartphone (yet). https://uk.pcmag.com/opinions/117014/4-reasons-ar-glasses-wont-replace-yoursmartphone-yet / Accessed 11 October 2018.

Dinh, H. Q., Walker, N., Song, C., Kobayashi, A., \& Hodges, L. F. (1999). Evaluating the importance of multi-sensory input on memory and the sense of presence in virtual environments. Proceedings of IEEE virtual reality, pp. 222-228.

Dorado, R., Chaya, C., Tarrega, A., \& Hort, J. (2016). The impact of using a written scenario when measuring emotional response to beer. Food Quality and Preference, 50, 38-47.

Etherington, D. (2016). AR in Mercedes-Benz's rescue assist app gives first responders an inside look. https://techcrunch.com/2016/07/27/ar-in-mercedes-benzs-rescue-assist-appgives-first-responders-an-inside-look/. Accessed 17 October 2018.

Filloon, W. (2016). Coke and McDonald's are now in the virtual reality business. https://www.eater.com/2016/3/2/11145714/coca-cola-mcdonalds-virtual-reality-headsets / Accessed 8 November 2018.

Flavián, C., Ibáñez-Sanchez, S., \& Orús, C. (2018). The impact of virtual, augmented and mixed reality technologies on the customer experience. Journal of Business Research, in press, https://doi.org/10.1016/j.jbusres.2018.10.050.

Gallace, A., Ngo, M.K., Sulaitis, J., \& Spence, C (2012). Multisensory presence in virtual reality: Possibilities \& Limitations. Multiple Sensorial Media Advances and Applications: New Developments in MulSeMedia, 1-38. 10.4018/978-1-60960-821-7.ch001.

Gallace, A., \& Spence, C. (2014). In touch with the future: the sense of touch from cognitive neurosciences to virtual reality. UK: Oxford University Press (Chapter 2).

Gibson, A., \& O'Rawe, M. (2018). Virtual reality as a travel promotional tool: insights from a consumer travel fair. In T. Jung, \& M. Claudia tom Dieck (Eds.), Augmented reality and virtual reality: Empowering human, place and business (pp. 93-107). Switzerland: Springer.

Hardawar, R. (2018). Tobii proves that eye tracking is VR's next killer feature. https://www.engadget.com/2018/01/13/tobii-vr-eye-tracking/ Accessed 29 October 2018. Harrar, V., and Spence, C. (2011). The taste of cutlery: how the taste of food is affected by the weight, size, shape, and colour of the cutlery used to eat it. Flavour, 2:21.

Harrar, V., Piqueras-Fiszman, B., Spence, C. (2011). There's no taste in a white bowl. Perception. 40: 880-892.

Hathaway, D., \& Simons, C.T. (2017). The impact of multiple immersion levels on data quality and panellist engagement for the evaluation of cookies under a preparation-based scenario. Food Quality and Preference, 57, 114-125. 
He, W., Boesveldt, S., de Graaf, C., de Wijk, R.A. (2016). The relation between continuous and discrete emotional responses to food odors with facial expressions and non-verbal reports. Food Quality and Preference, 48, 130-137.

Hein, K.A., Hamid, N., Jaeger, S.A., \& Delahunty, C.M. (2010). Application of a written scenario to evoke a consumption context in a laboratory setting: Effects on hedonic ratings. Food Quality and Preference, 21, 410-416.

Holthuysen, N.T.E., Vrijhof, M.N., de Wijk, R.A., \& Kremer, S. (2017). Welcome on board: Overall liking and just-about-right ratings of airplane meals in three different consumption contexts: laboratory, re-created airplane, and actual airplane. Journal of Sensory Studies, 32, e12254.

Jaeger, S.R., Hort, J., Porcherot, C., Ares, G., Pecore, S., \& MacFie, H.J.H. (2017). Future directions in sensory and consumer science: Four perspectives and audience voting. Food Quality and Preference, 56, 301-309.

Jaeger, S.R., \& Porcherot, C. (2017). Consumption context in consumer research: methodological perspectives. Current Opinion in Food Science, 15, 30-37.

Jaeger, S.R., Swaney-Stueve, M., Chheang, S.L., Hunter, D.C., Pineau, B., \& Ares, G. (2018). An assessment of the CATA-variant of the EsSense Profile ${ }^{\circledR}$. Food Quality and Preference, 68, 360-370.

Kampfer, K., Leischnig, A., Sven Ivens, B., \& Spence, C. (2017). Touch-flavor transference: Assessing the effect of packaging weight on gustatory evaluations, desire for food and beverages, and willingness to pay. Plos One, 12 (10): e0186121.

Kantono, K., Hamid, N., Shepherd, D., Yoo, M.J.Y., Grazioli, G., \& Carr, T. (2016). Listening to music can influence hedonic and sensory perceptions of gelati. Food Quality and Preference, $100,244-255$.

Kemp, S., Ng, M., Hollowood, T., \& Hort, H. (2018). Introduction to descriptive analysis. In S.E. Kemp, J. Hort., \& T. Hollowood (Eds.), Descriptive analysis in sensory evaluation (pp. 341). UK: John Wiley \& Sons Ltd.

Kiefer, B. (2017). How Guinness and R/GA made a VR tasting experience for all five senses. https://www.campaignlive.co.uk/article/guinness-r-ga-made-vr-tasting-experience-fivesenses/1434731 / Accessed 8 November 2018.

Kim, S.O., Lee, S.M., \& Kim, K.O. (2016). Consumer acceptability of coffee as affected by situational conditions and involvement. Food Quality and Preference, 52, 124-132.

Kim, T., Hwang, S., Kim, S., Ahn, H., \& Chung, D. (2016). Smart contact lenses for augmented reality and methods of manufacturing and operating the same. US Patent No: 2016009 1737A1. 
Kipper, G., \& Rampolia, J. (2013). Augmented reality: An emerging technologies guide to AR. USA: Elsevier.

Korsgaard, D., Bjoner, T., \& Nilsson, N.C. (2018). Where would you like to eat? A formative evaluation of mixed-reality solitary meals in virtual environments for older adults with mobility impairments who live alone. Food Research International, in press: https://doi.org/10.1016/j.foodres.2018.02.051.

Köster, E. P. (2009). Diversity in the determinants of food choice: A psychological perspective. Food Quality and Preference, 20, 70-82.

Lamkin, P. (2017). Virtual reality headset sales hit 1 million. https://www.forbes.com/sites/paullamkin/2017/11/30/virtual-reality-headset-sales-hit-1million/\#7554b7882b61/ Accessed 20 November 2018.

Lamkin, P. (2018). The best augmented reality glasses 2018: Snap, Vuzix, ODG, Sony \& more. https://www.wareable.com/ar/the-best-smartglasses-google-glass-and-the-rest / Accessed 12 October 2018.

Lanier, L. (2018). Pokemon Go reaches 800 million downloads. https://variety.com/2018/gaming/news/pokemon-go-downloads-1202825268/ Accessed 14 October 2018.

Lauria, R.M., \& Ford-Morie, J. (2015). Virtuality: VR as metamedia and herald of future realities. In L. Cantoni., \& J.A. Danowski (Eds.), Communication and Technology (pp. 141 147). Germany: CPI Books.

Lawson, G., Salanitri, D., \& Waterfield, B. (2016). Future directions for the development of virtual reality within an automotive manufacturer. Applied Ergonomics, 53, 323-330.

Léonard, A., Blacher, S., Nimmol, C. \& Devahastin, S. (2008). Effect of infra-red radiation assisted drying on microstructure of banana slices: an illustrative use of $\mathbf{x}$-ray microtomography in microstructural evaluation of a food product. Journal of Food Engineering, 85, 154-162.

Linowes, J., \& Babilinski, K. (2017). Augmented reality for developers: Build practical augmented reality applications with Unity, ARCore, ARKit, and Vuforia. UK: Packt Publishing. Lowood, H.E. (2018). Virtual reality, Encyclopaedia Britannica. https://www.britannica.com/technology/virtual-reality/ Accessed 16 October 2018.

Mealy, P. (2018). Virtual \& augmented reality for dummies. USA: John Wiley \& Sons.

Merchant, Z., Goetz, E.T., Cifuentes, L., Keeney-Kennicutt, W., \& Davis, T.J. (2014). Effectiveness of virtual reality-based instruction on students' learning outcomes in K-12 and higher education: A meta-analysis. Computers \& Education, 70, 29-40. 
Michail, N, (2017). From marketing to taste: how virtual reality will change the food industry. https://www.beveragedaily.com/Article/2017/03/07/From-marketing-to-tasteHow-virtual-reality-will-change-the-food-industry / Accessed 8 November 2018.

Moeller, I. (2018). New trends in biometrics with Isabelle Moeller from the Biometrics Institute. https://www.gemalto.com/govt/biometrics/trends-in-biometrics / Accessed 29 October 2018.

Nakamura, H., \& Miyashita, H. (2013). Controlling saltiness without salt: Evaluation of taste change by applying and releasing cathodal current. Proceedings of the 5th international workshop on multimedia for cooking \& eating activities, 9-14.

Narumi, T., Nishizaka, S., Kajinami, T., Tanikawa, T., \& Hirose., M (2011). Meta Cookie+: An Illusion-Based Gustatory Display. In: R. Shumaker (Ed.), Virtual and Mixed Reality: New Trends: Lecture Notes in Computer Science, 6773, Germany: Springer.

Narumi, T., Ban, Y., Kajinami, T., Tanikawa, \& Hirose, M. (2012). Augmented perception of satiety: controlling food consumption by changing apparent size of food with augmented reality. Proceedings of the SIGCHI Conference on Human Factors in Computing Systems, 109-118.

Nishizawa, M., Jiang, W., \& Okajima, K. (2016). Projective-AR system for customizing the appearance and taste of food. Proceedings of the 2016 workshop on Multimodal Virtual and Augmented Reality, 6.

Ng, M., Chaya, C., \& Hort, J. (2013). Beyond liking: Comparing the measurement of emotional response using EsSense Profile and consumer defined check-all-that-apply methodologies. Food Quality and Preference, 28, 193-205.

Ong, S.K., \& Nee, A.Y.C. (2004). A brief introduction of VR and AR applications in manufacturing. In S.K. Ong , \& A.Y.C. Nee (Eds.), Virtual and augmented reality applications in manufacturing (pp. 1-14). London: Springer.

Palladino, T. (2018). UK's largest children's hospital is adopting HoloLens to assist surgeons. https://hololens.reality.news/news/uks-largest-childrens-hospital-is-adopting-hololensassist-surgeons-0186495/ Accessed 13 November 2018.

Perret, J., \& Vander-Poorten, E. (2018). Touching virtual reality: a review of haptic gloves. Conference paper at ACTUATOR, Bremen, Germany.

Persky, S., Goldring, M.R., Turner, S.A., Cohen, R.W., \& Kistler, W.D. (2018). Validity of assessing child feeding with virtual reality. Appetite, 123, 201-207.

Petit, O., Cheok, A.D., Spence, C., Velasco, C., \& Karunanayaka, K.T. (2015). Sensory marketing in light of new technologies. Proceedings of the 12th International Conference on Advances in Computer Entertainment Technology, 53. 
Pfurtscheller, G., Leeb, R., Keinrath, C., Friedman, D., Neuper, C., Guger, C., \& Slater, M. (2006). Walking from thought. Brain Research, 107, 145-152.

Piqueras-Fiszman, B., Alcaide, J., Roura, E., \& Spence, C. (2012). Is it the plate or is it the food? Assessing the influence of the color (black or white) and shape of the plate on the perception of the food placed on it. Food Quality and Preference, 24, 205-208.

Porcherot, C., Delplanque, S., Gaudreau, N., Ischer, M., De Marles, A., \& Cayeux, I. (2018). Immersive techniques and virtual reality. In G.A. Áres, \& P. Varela (Eds.), Methods in consumer research: alternative approaches and special applications (pp. 69-80). UK: Elsevier.

Powell, S. (2018). Uncle Ben's using augmented reality to reveal rice supply chain. https://thefuturescentre.org/signals-of-change/218004/uncle-bens-using-augmentedreality-reveal-rice-supply-chain / Accessed 22 November 2018.

Ranasinghe, N., Tolley, D., Nguyen, T.N.T., Yan, L., Chew, B., \& Yi-Luen Do, E. (2018). Augmented flavours: Modulation of flavour experiences through electric taste augmentation. Food Research International, in press: https://doi.org/10.1016/j.foodres.2018.05.030

Ranasinghe, N., Nakatsu, R., Nii, H., \& Gopalakrishnakone, P. (2012). Tongue mounted interface for digitally actuating the sense of taste. Proceedings of the 16th Annual International Symposium on Wearable Computers, 80-87.

Ranasinghe, N., Lee, K.Y., Suthokumar, G., \& Do, E. Y.L. (2016). Virtual ingredients for food and beverages to create immersive taste experiences. Multimedia Tools and Applications, 75, 12291-12309.

Reddivari, S., Smith, J., \& Pabalate, J. (2017). VRVisu: a tool for virtual reality based visualization of medical data. Proceedings of the Second IEEE/ACM International Conference on Connected Health: Applications, Systems and Engineering Technologies, 280-281.

Risso, P., Rodriguez, M.C., Bordegoni, M., \& Gallace, A. (2018). Development and testing of a small-size olfactometer for perception of food and beverages in humans. Frontiers in Digital Humanities, doi.org/10.3389/fdigh.2018.00007.

Robertson, A. (2018). Bose's augmented reality glasses use sound instead of sight. https://www.theverge.com/2018/3/12/17106688/bose-ar-audio-augmented-realityglasses-demo-sxsw-2018 / Accessed 12 October 2018.

Rollo, M.E., Bucher, T., Smith, S.P., \& Collins, C.E (2017). ServAR: An augmented reality tool to guide the serving of food. International Journal of Behavioral Nutrition and Physical Activity, 14:65. 
Santagiuliana, M., Christaki, M., Piqueras-Fiszman, B., Scholten, E., \& Stieger, M. (2018). Effect of mechanical contrast on sensory perception of heterogeneous liquid and semi-solid foods. Food Hydrocolloids, 83, 202-212.

Schnack, A., Wright, M.J., \& Holdershaw, J.L. (2018). Immersive virtual reality technology in a three-dimensional virtual simulated store: Investigating telepresence and usability. Food Research International, in press: https://doi.org/10.1016/j.foodres.2018.01.028.

Schoeman, L., Williams, P., du Plessis, A. \& Manley, M. (2016). X-ray micro-computed tomography $(\mu \mathrm{CT})$ for non-destructive characterisation of food microstructure. Trends in Food Science and Technology, 47, 10-24.

Sester, C., Deroy, O., Sutan, A., Galia, F., Desmarchelier, J-F., Valentin, D. \& Dacremont, D. (2013). 'Having a drink in a bar: An immersive approach to explore the effects of context on drink choice. Food Quality and Preference, 28, 23-31.

Siegrist, M., Leins-Hess, R., \& Keller, C. (2015). Which front-of-pack nutrition label is the most efficient one? The results of an eye-tracker study. Food Quality and Preference, 39, 183-190.

Siegrist, M., Ung, C.Y., Zank, M., Marinello, M., Kunz, A., Hartmann, C., Menozzi, M. (2018). Consumers' food selection behaviors in three-dimensional (3D) virtual reality. Food Quality and Preference, in press: https://doi.org/10.1016/j.foodres.2018.02.033.

Silva, J.N.A., Southworth, M., Raptis, C., \& Silva, J. (2018). Emerging applications of virtual reality in cardiovascular medicine. JACC: Basic to Transitional Science, 3, 420-430.

Singh, P. and Erdogdu, F. (2004). Virtual Experiments in Food Processing, RAR Press.

Spence, C. (2019). Multisensory experiential wine marketing. Food Quality and Preference, $71,106-116$

Spence, C. (2015a). Eating with our ears: assessing the importance of the sounds of consumption on our perception and enjoyment of multisensory flavour experiences. Flavour, 4:3.

Spence, C. (2015b). Leading the consumer by the nose: on the commercialization of olfactory design for the food and beverage sector. Flavour, 4:31.

Stefani, C., Lacy-Hulbert, A., \& Skillman, T. (2018). ConfocalVR: Immersive Visualization for Confocal Microscopy. Journal of Molecular Biology, 430, 4028-4035.

Stelick, A., Penano, A.G., Riak, A.C., \& Dando, R. (2018). Dynamic context sensory testing: A proof of concept study bringing virtual reality to the sensory booth. Journal of Food Science, 83, 2047-2051. 
Stokes, J., Boehm, M.W., \& Baier, S.K. (2013). Oral processing, texture and mouthfeel: From rheology to tribology and beyond. Current Opinion in Colloid \& Interface Science, 18, 349359.

Sutherland, J., \& La Russa, D. (2017) Virtual reality. In F.J. Rybicki, \& G.T. Grant (Eds.), 3D Printing in Medicine A Practical Guide for Medical Professionals (pp. 125-133). Switzerland: Springer.

Swaminathan, A., \& Ramachandran, M. (2018). Enabling augmented reality using eye gaze tracking. US Patent No: US9996150B2.

Torrico, D.D., Fuentes, S., Gonzalez-Viejo, C., Ashman, H., Gunaratne, N.M., Gunaratne, T.M., \& Dunshea, F.R. (2018a). Images and chocolate stimuli affect physiological and affective responses of consumers: A cross-cultural study. Food Quality and Preference, 65, 60-71.

Torrico, D.D., Hutching, S.C., Ha, M., Bittner, E.P., Fuentes, S., Warner, R.D., \& Dunshea, F.R. (2018b). Novel techniques to understand consumer responses towards food products: A review with a focus on meat. Food Quality and Preference, 144, 30-42.

Tuorila, H., \& Monteleone, E. (2009). Sensory food science in the changing society: Opportunities, needs, and challenges. Trends in Food Science and Technology, 20, 54-62.

Velasco, C., Obrist, M., Petit, O., \& Spence, C. (2018). Multisensory technology for flavor augmentation: A mini review. Frontiers in Psychology, 9, 26.

Verastegui-Tena, L., van Trijp, H., \& Piqueras-Fiszman, B. (2019). Heart rate, skin conductance, and explicit responses to juice samples with varying levels of expectation (dis)confirmation. Food Quality and Preference, 71, 320-331.

Verhulst, A., Normand, J.A., Lombard, C.., \& Moreau, G. (2017). A study on the use of an immersive virtual reality store to investigate consumer perceptions and purchase behavior toward non-standard fruits and vegetables. Paper presented at the IEEE Virtual Reality (VR), Los Angeles, USA (March 18-22).

Viemose, I., Moller,P., Laugesen, J.L., Schacthman, T.R., Manoharan, T., \& Christoffersen, G.R.J. (2013). Appetitive long-term taste conditioning enhances human visually evoked EEG responses. Behavioural Brain Research, 253, 1-8.

Warren, T. (2018). A closer look at HTC's new higher-resolution Vive Pro. https://www.theverge.com/2018/1/9/16866240/htc-vive-pro-vr-headset-hands-on-ces2018/ Accessed 20 November 2018.

Watson, E. (2018). Augmented reality and packaging: a passing fad or a limitless digital canvas for tomorrow's food marketers? https://www.foodnavigatorusa.com/Article/2017/08/07/Augmented-reality-and-food-packaging-Where-next / Accessed 22 November 2018. 
Wheeler, G., Deng, S., Toussaint, N., Pushparajah, K., Schnabel, J.A., Simpson, J.M., \& Gomez, A. (2018). Virtual interaction and visualisation of 3D medical imaging data with VTK and Unity. Healthcare Technology Letters, 5, 148-153.

Witt, T., \& Stokes, J.R. (2015). Physics of food structure breakdown and bolus formation during oral processing of hard and soft solids. Current Opinion in Food Science, 3, 110-117.

Ung, C.Y., Menozzi, M., Hartmann, C., \& Siegrist, M. (2018). Innovations in consumer research: the virtual food buffet. Food Quality and Preference, 63, 12-17. 
Fig.1. Loaf of bread imaged using computed tomography (CT) and Arivis Vision 4D software (Arivis AG, Erika-Mann-Straße 23, 80636 Munich, Germany).

Fig.2. Visualisation of an AR nutritional label for a $450 \mathrm{~g}$ portion of beef lasagne 


\section{Highlights}

- Recent advancements in virtual and augmented reality technologies are reviewed

- Emerging applications for VR and AR in sensory science are identified

- Key areas in which VR and AR may prove valuable in sensory science are identified

- Future research will identify how VR/AR can be integrated with food/human responses

\section{Key words}

Virtual reality, augmented reality, emerging technologies, sensory science

\section{Industrial relevance}

The need for sensory evaluation within the food industry is becoming increasingly complex as companies continuously compete for consumer product acceptance in today's highly innovative and global food environment. Recent technological developments in virtual and augmented reality offer the food industry new opportunities for generating more reliable insights into consumer sensory perceptions of food and beverages, contributing to the design and development of new products with optimised consumer benefits. These technologies also hold significant potential for improving the predictive validity of newly launched products within the marketplace. 


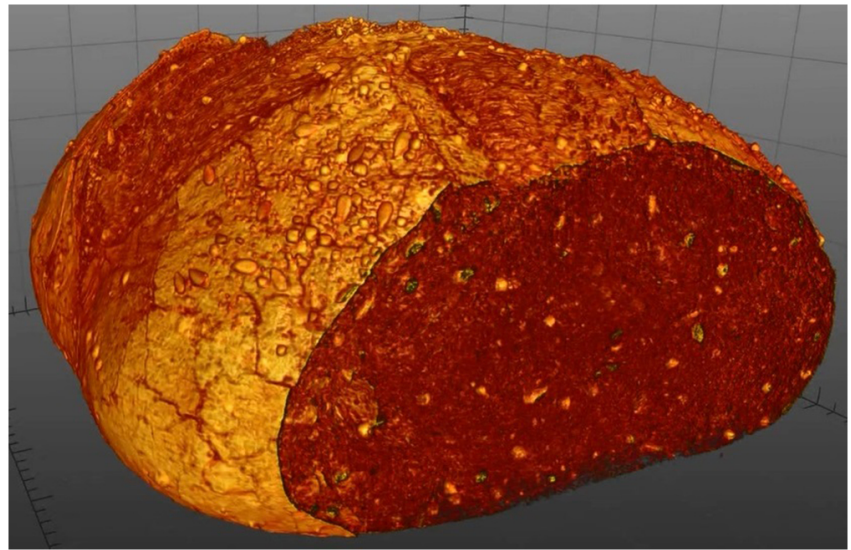

Figure 1 


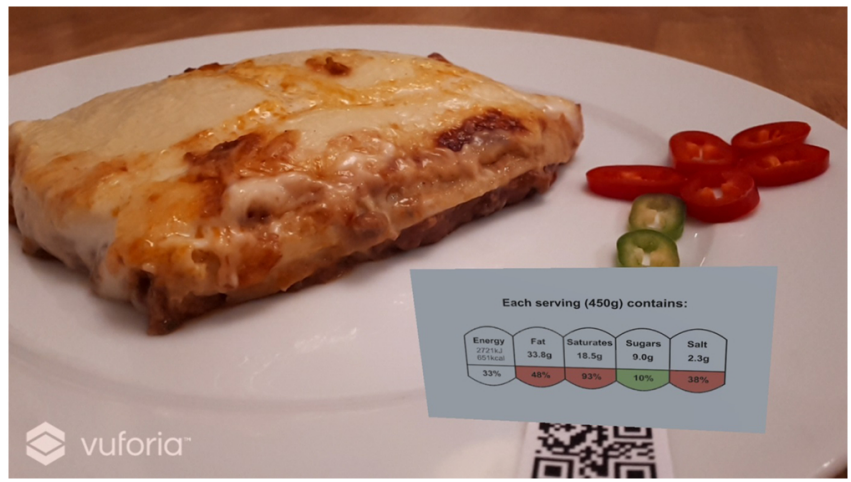

Figure 2 